\title{
The protein kinase $M \zeta$ network as a bistable switch to store neuronal memory
}

\author{
Hideaki Ogasawara ${ }^{1,2,3^{*}}$, Mitsuo Kawato ${ }^{2}$
}

\begin{abstract}
Background: Protein kinase $M \zeta(P K M \zeta)$, the brain-specific, atypical protein kinase $C$ isoform, plays a key role in long-term maintenance of memory. This molecule is essential for long-term potentiation of the neuron and various modalities of learning such as spatial memory and fear conditioning. It is unknown, however, how PKM information for long periods of time despite molecular turnover.

Results: We hypothesized that PKM forms a bistable switch because it appears to constitute a positive feedback loop (PKM $\zeta$ induces its local synthesis) part of which is ultrasensitive (PKM $\zeta$ stimulates its synthesis through dual pathways). To examine this hypothesis, we modeled the biochemical network of PKM $\zeta$ with realistic kinetic parameters. Bifurcation analyses of the model showed that the system maintains either the up state or the down state according to previous inputs. Furthermore, the model was able to reproduce a variety of previous experimental results regarding synaptic plasticity and learning, which suggested that it captures the essential mechanism for neuronal memory. We proposed in vitro and in vivo experiments that would critically examine the validity of the model and illuminate the pivotal role of PKM in synaptic plasticity and learning.

Conclusions: This study revealed bistability of the PKM storage of memory.
\end{abstract}

\section{Background}

Protein kinase $\mathrm{M \zeta}(\mathrm{PKM} \zeta)$ is increasingly drawing attention as a molecule that maintains neuronal memory for an extremely long period of time [1]. It is a brain-specific atypical protein kinase $\mathrm{C}(\mathrm{PKC})$ isoform that lacks a regulatory domain, rendering it constitutively active [2]. PKM $\zeta$ enhances excitatory postsynaptic currents (EPSCs) and leads to the long-term potentiation (LTP) of synapses by stabilizing $\alpha$-amino-3-hydroxy-5-methyl4-isoxazolepropionic acid (AMPA)-type glutamate receptors through an $\mathrm{N}$-ethylmaleimide-sensitive factor (NSF)/GluR2-dependent pathway [3-5]. The messenger ribonucleic acid (mRNA) for PKM $\zeta$ is found in various brain areas, including the hippocampus, striatum, neocortex, thalamic nuclei, and cerebellar cortex and localizes to spiny dendrites of neurons [6]. PKM $\zeta$ is translated within only ten minutes in response to LTPinducing stimuli $[2,7]$, suggesting its local synthesis.

\footnotetext{
* Correspondence: ogahide.res@gmail.com

${ }^{1}$ National Institute of Information and Communications Technology, 2-2-2, Hikaridai, Seika, Kyoto 619-0288, Japan

Full list of author information is available at the end of the article
}

The use of a specific inhibitor, $\zeta$-inhibitory protein (ZIP) [8], has elucidated the pivotal role of PKM $\zeta$ in synaptic plasticity, learning, and memory. The late phase of LTP (L-LTP) in a hippocampal slice is reversed by ZIP administration [9], indicating that LTP maintenance requires PKM . PKM $\zeta$ plays crucial roles in various modalities of learning, including spatial memory of the hippocampus and fear conditioning of the basal lateral amygdala, as evidenced by memory erasure following ZIP microinjection [10]. In rats, consolidated memory is sensitive to ZIP for at least one month [11].

PKM $\zeta$ appears to constitute a positive feedback loop $[1,12,13]$. ZIP administration prevents hippocampal neurons from expressing PKM $\zeta$ protein when these neurons are treated with a tetanus that would normally induce LTP and PKM $\zeta$ expression [12], indicating that PKM $\zeta$ activity is necessary for PKM $\zeta$ synthesis. We previously posed the possibility that the PKM $\zeta$ network is bistable [13], since biochemical positive feedback loops often offer bistability [14,15]. Bistable positive feedback loops of enzymatic reactions may provide a basis for cellular memory $[16,17]$.

C Biomed Central

(c) 2010 Ogasawara and Kawato; licensee BioMed Central Ltd. This is an Open Access article distributed under the terms of the Creative Commons Attribution License (http://creativecommons.org/licenses/by/2.0), which permits unrestricted use, distribution, and reproduction in any medium, provided the original work is properly cited. 
Our previous model $[13,18]$ conceptually illustrated that memory plasticity and stability can be both achieved by a cascade of multiple nonlinear or bistable dynamics that have various time constants and are connected in tandem in the order of fast to slow. Once the cascade is stimulated, activity is transmitted from a fast dynamic to a slower dynamic before the faster dynamic loses its activity; finally, the slowest dynamic is turned on. Hippocampal LTP appears to occur in line with this model. LTP-inducing stimuli trigger a supralinear calcium increase in dendritic spines that lasts for seconds [19-22]. Then, calcium activates protein kinases such as $\mathrm{Ca}^{2+} /$ calmodulin-dependent protein kinase (CaMKII) in a supralinear manner and maintains their activity for tens of minutes [23,24]. Finally, CaMKII and other protein kinases induce longer-lasting PKM $\zeta$ expression [12] probably in an all-or-none manner [13].

To evaluate our hypothesis that the PKM $\zeta$ network is bistable and functions as neuronal memory, we performed simulations and bifurcation analyses in the Results section. Very simple though our model was, it was able to reproduce various experimental results. Moreover, in the Discussion section, we proposed yet to be done experiments that would critically examine our hypothesis. Although ZIP is regarded as a specific inhibitor of $\mathrm{PKM} \zeta$, it might inhibit other protein kinases as well. In this paper, therefore, we use the term 'PKM $\zeta$ ' to collectively refer to ZIP-sensitive protein kinases including PKM $\zeta$.

\section{Results}

Description of the model

Figure 1 illustrates the molecular pathways of the PKM network model. The model is described by three ordinary differential equations (ODEs), Equations 1-3 (see Methods). A time-dependent variable, Stim(t), represents the aggregate activity of protein kinases that trigger PKM $\zeta$ expression, such as CaMKII, PKC, and mitogen-activated protein kinase (MAPK) (Figure 1, arrow 1) $[2,7]$. In reality, these protein kinases act through various pathways to turn on the PKM $\zeta$ network. However, since the purpose of the model was to mathematically analyze the dynamics of the network, kinasic activation of the network was simplified as a single variable. Experiments have shown that the PKM $\zeta$ protein stimulates translation of its own mRNA into protein (Figure 1, arrow 2) [25], forming a positive feedback loop. At the same time, its PKC activity presumably promotes actin polymerization (Figure 1, arrow 3) [26-29], and F-actin (actin polymer) facilitates general protein synthesis (Figure 1, arrow 4) [30,31]. This convergence of the two pathways is likely to make the system more sensitive to differences in stimulus size than the standard Michaelis-Menten kinetics (ultrasensitivity). A

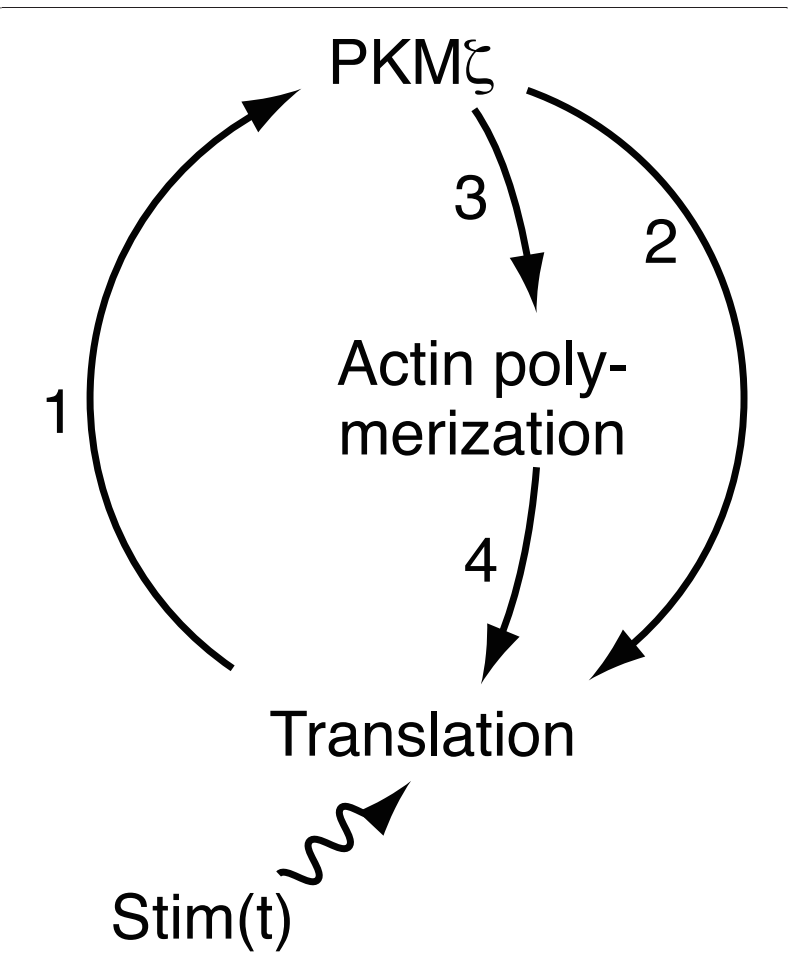

Figure 1 The PKM $\zeta$ network model. See text for explanation.

mathematical theory states that a combination of ultrasensitivity and positive feedback possibly results in bistability [15], which we examine in the following section.

\section{Bistability of the PKM $\zeta$ network}

We stimulated the model with a square wave, $\operatorname{Stim}(\mathrm{t})=$ 5 , 25 or $125(0 \leq t<30)$, to observe the time course of [PKM $\zeta$ ] (Figure 2A). EPSC amplitudes (Figure 2B) were estimated by time-integrating [PKM $\zeta$ ] (Equation 4 in Methods). In this model, the concentrations of molecules, strength of Stim, and EPSC are unitless values, and EPSC amplitudes of 1 and 2 correspond to the
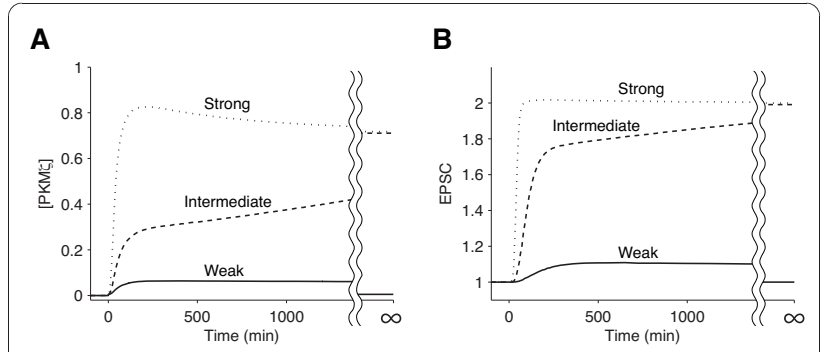

Figure 2 Time courses of A) [PKM $\zeta$ ] and B) EPSC amplitude. A weak (Stim $=5$, solid line), intermediate (Stim $=25$, dashed line) or strong (Stim $=125$, dotted line) stimulus was given for 30 minutes. Stimulus strength, [PKM $\zeta$ ], and EPSC amplitude are unitless values. 
unpotentiated and potentiated states, respectively. When the stimulus was weak $($ Stim $=5),[\mathrm{PKM} \zeta]$ rose transiently but ended up at zero, and EPSC was enhanced transiently. When the stimulus was intermediate (Stim = 25), [PKM $\zeta]$ reached a value of 0.72 asymptotically, and EPSC amplitude reached a value of 2 . When the stimulus was strong $($ Stim $=125)$, [PKM $]$ ] overshot before asymptotically reaching a value of 0.72 , and EPSC amplitude approached a value of 2 asymptotically.

We then varied the duration and strength of Stim $(t)$ to see whether $[\mathrm{PKM} \zeta]$ can reach any steady state other than $[\mathrm{PKM} \zeta]_{\mathrm{t}=\infty}=0$ or 0.72 . In the two-dimensional parameter space (Figure 3A) with respect to the strength (abscissa) and duration (ordinate), $[\mathrm{PKM} \zeta]_{\mathrm{t}}=\infty$ was either 0 (gray) or 0.72 (white), and not intermediate anywhere. Stimuli that were longer or shorter in duration required a weaker or stronger strength, respectively, to turn on the $\mathrm{PKM} \zeta$ network. As expected, EPSC amplitude reached a value of only either 1 or 2 (Figure 3B), and the areas for $\mathrm{EPSC}_{\mathrm{t}=\infty}=1$ and $\mathrm{EPSC}_{\mathrm{t}=\infty}=2$ were identical to the areas for $[\mathrm{PKM} \zeta]_{\mathrm{t}=\infty}=0$ and $[\mathrm{PKM} \zeta]_{\mathrm{t}=\infty}=0.72$, respectively. This switch-like behavior indicated high nonlinearity of the system.

Up to this point, we have shown that the PKM $\zeta$ network responds to stimuli in an all-or-nothing manner (Figures 2 and 3). Next, we performed a bifurcation analysis [32-34] to further illuminate the dynamics of the model and evaluate its parameter dependence. The model has seven parameters, including the rate parameters $j_{1}, j_{2}, j_{3}$, and $j_{4}$ and three time constants (see Methods), but we only needed to analyze the model with respect to the four rate parameters because the time constants do not affect the model equilibria (see additional file 1$). j_{1}$ denotes the PKM $\zeta$ synthesis rate relative to its decay rate, $j_{2}$ and $j_{3}$ denote the $\mathrm{PKM} \zeta$ independent and PKM $\zeta$-dependent actin polymerization rates relative to the actin depolymerization rate, respectively, and $j_{4}$ denotes the rate at which PKM $\zeta$ mRNA is incorporated into the translational machinery relative to the rate of mRNA detachment from the machinery.
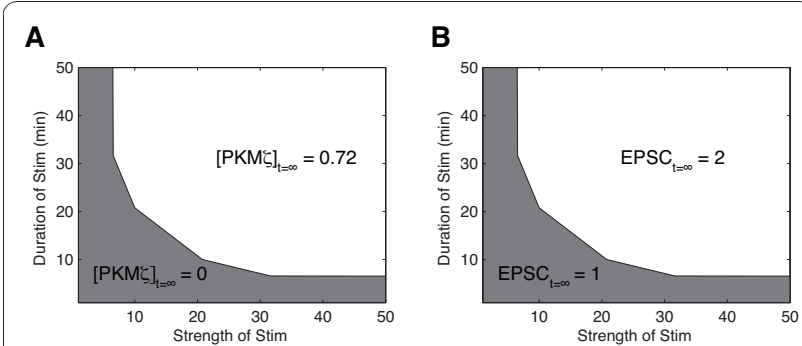

Figure 3 Steady-state A) [PKM $]$ ] and B) EPSC amplitude after various strengths and durations of Stim were given. The strength and duration of Stim are shown on the abscissa and the ordinate, respectively.
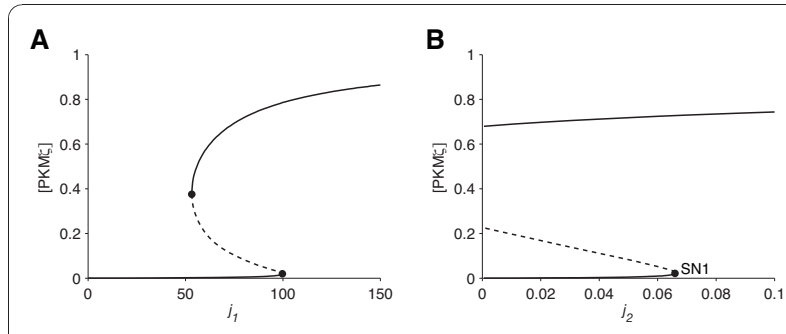

C

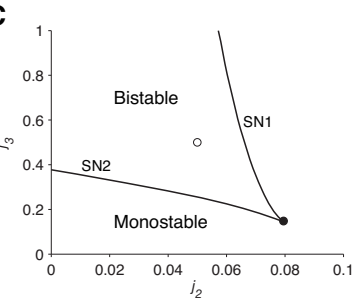

D
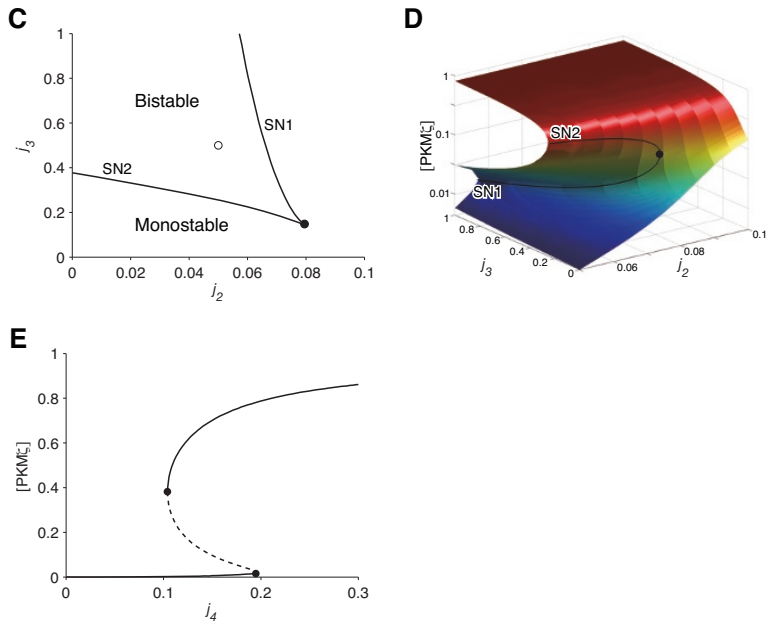

Figure 4 Bifurcation analyses. A) Bifurcation diagram with respect to the PKM $\zeta$ synthesis rate, $j_{1}$. B) Bifurcation analysis with respect to the PKM $\zeta$-independent actin polymerization rate, $j_{2}$. Only one (SN1) of the two saddle node bifurcations is seen in this plot. C, D) Twoparameter bifurcation analysis with respect to $j_{2}$, and the PKM $\zeta$ dependent actin polymerization rate, $j_{3}$. C) A two-dimensional plot with $j_{2}$ in the $X$-axis and $j_{3}$ in the $Y$-axis. D) A three-dimensional plot with $j_{2}$ in the $X$-axis, $j_{3}$ in the $Y$-axis, and steady-state [PKM $\zeta$ ] in the $Z$-axis (log scale). E) Bifurcation analysis with respect to $j_{4}$, the rate at which PKM $\mathrm{mRNA}$ is incorporated into the translational machinery. In panels A, B, and $E$, the solid and dashed lines indicate [PKM $\zeta$ ] at stable and unstable steady states, respectively; the circles denote saddle-node bifurcations. In panels C and D, the solid lines, solid circles, and open circle (only in panel C) indicate saddle-node bifurcations (SN1 and SN2), the cusp bifurcation point, and the default values of $j_{1}$ and $j_{2}$, respectively.

First, we varied the PKM $\zeta$ synthesis rate $j_{1}$ and tracked the equilibrium points of the model (Figure 4A). The horizontal and vertical axes show $j_{1}$ and steady-state $[\mathrm{PKM} \zeta]$, respectively. The two solid lines denote stable steady states: the UP state (upper) and the DOWN state (lower). There were two saddle-node bifurcations (circles) at $j_{1}=53$ and $j_{1}=100$. When $j_{1}<$ 53 , only the DOWN state was stable; when $j_{1}>100$, only the UP state was stable. When $53 \leq j_{1} \leq 100$, the system was bistable at the two stable steady states, the UP and DOWN states, which were separated by an unstable steady state (dashed line). The default value of $j_{1}$ was 80 and within the range of bistability.

Next, we performed a bifurcation analysis with respect to the $\mathrm{PKM} \zeta$-independent actin polymerization rate $j_{2}$ 
and the PKM $\zeta$-dependent polymerization rate $j_{3}$. Figure $4 \mathrm{~B}$ shows $j_{2}$ on the horizontal axis and steadystate $[\mathrm{PKM} \zeta]$ on the vertical axis. There was a saddlenode bifurcation $(\mathrm{SN} 1)$ at $j_{2}=0.066$, and the system was bistable when $j_{2}<0.066$ and monostable at the UP state when $j_{2} \geq 0.066$. To further characterize the actin polymerization rates-dependent dynamics of the model, we performed two-parameter bifurcation analysis with respect to $j_{2}$ and $j_{3}$ (Figures $4 \mathrm{C}$ and $4 \mathrm{D}$ ). The analysis revealed that two branches of the saddle node bifurcation curve (solid lines, SN1 and SN2) met tangentially at a point (solid circle). This type of bifurcation is mathematically termed the "cusp bifurcation" [34]. The parameter regions of monostability and bistability are indicated in Figure 4C. Loss of bistability at small values of $j_{2}$ and $j_{3}$ indicates that the F-actin-dependent facilitation of protein synthesis is essential for the bistability of the PKM $\zeta$ network.

Lastly, we performed a bifurcation analysis in terms of $j_{4}$, the rate at which $\mathrm{PKM} \zeta \mathrm{mRNA}$ is incorporated into the translational machinery (Figure $4 \mathrm{E}$ ). The system was monostable at the DOWN state when $j_{4}<0.10$ and at the UP state when $\mathrm{j}_{4}>0.19$. It was bistable when $0.10 \leq$ $j_{4} \leq 0.19$. The PKM $\zeta$ network was shown to be bistable over wide ranges of the parameters $j_{1}, j_{2}, j_{3}$, and $j_{4}$, indicating its suitability as an engram.

\section{Comparison with previous experiments}

Next, we simulated a variety of previous experiments to examine whether the model was able to explain their results.

\section{PKM $\zeta$ inhibition}

ZIP reverses LTP in hippocampal neurons even when applied five hours after LTP-inducing stimuli [9], indicating the essential role of PKM $\zeta$ in L-LTP. We simulated this experiment by starting from the UP state and temporarily clamping $[\mathrm{PKM} \zeta]$ at zero for 60 minutes. The simulated time courses of [PKM $\zeta$ ] and EPSC amplitude are plotted in Figures 5A and 5B. When PKM $\zeta$ was eliminated, EPSC amplitude began to gradually decrease. When $[\mathrm{PKM} \zeta]$ was unclamped at $\mathrm{t}=60$, it increased slightly, hit a peak, and decreased again, whereas EPSC amplitude constantly approached the DOWN state. Thus, the simulation result is consistent with the experimental result [9].

\section{PKM $\zeta$ introduction}

The introduction of exogenous $\mathrm{PKM} \zeta$ has been shown to be sufficient to induce LTP in CA1 pyramidal neurons [25]. We simulated this finding by fixing [PKM $\zeta]$ at 10 for 5 minutes to mimic exogenous PKM $\zeta$. The simulated time courses of endogenous [PKM $\zeta$ ] and EPSC amplitude are shown in Figures 5C and 5D. Similar to the experimental result, transient application of exogenous PKM $\zeta$ activated PKM $\zeta$ production and turned on
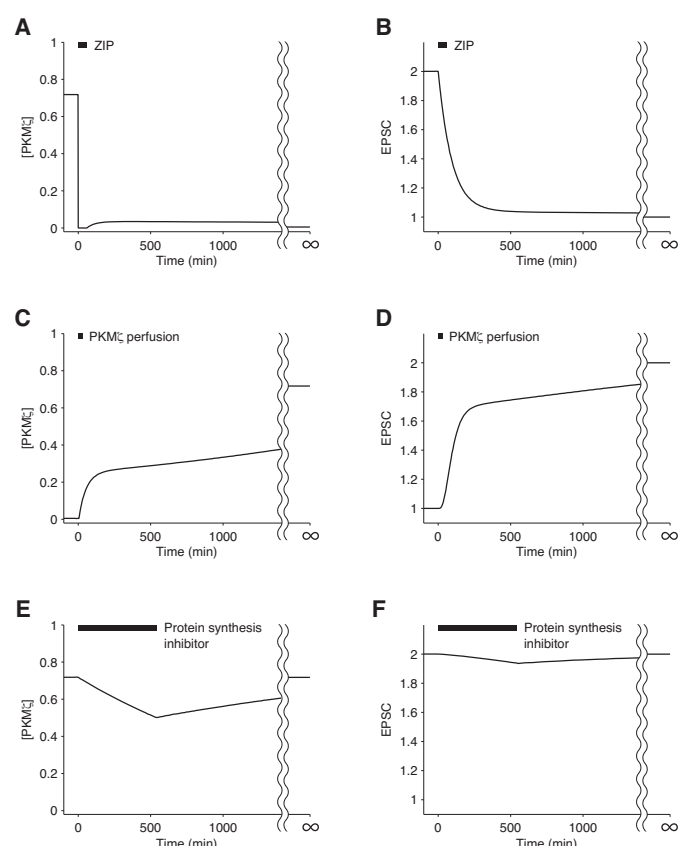

$\mathbf{F}$
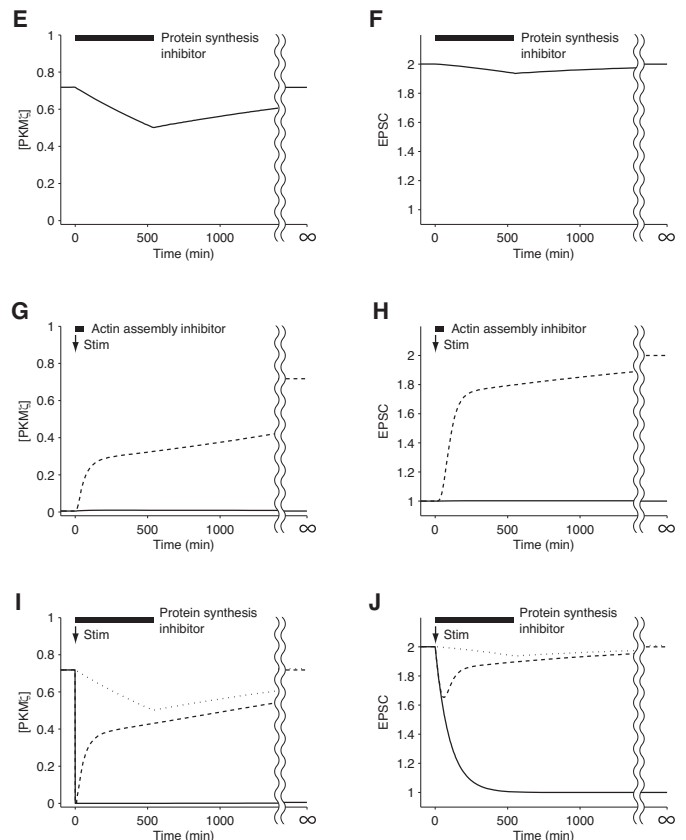

Figure 5 Simulations reproducing previous experimental results. Time courses of [PKM C] (panels $A, C, E, G, I$ ) and EPSC amplitude (panels $B, D, F, H, J$ ) are shown. A, B) ZIP administration to a potentiated synapse. C, D) PKM synthesis inhibitor administration to a potentiated synapse. $\mathrm{G}, \mathrm{H}$ ) Stimulation in the presence (solid line) or absence (dashed line) of an actin assembly inhibitor. I, J) Reactivation in the presence (solid line) or absence (dashed line) of protein synthesis inhibitor. The dotted line corresponds to protein synthesis inhibition without reactivation. Arrows and bold bars indicate the onset of an LTPinducing stimulus, $\operatorname{Stim}(\mathrm{t})=25(0 \leq \mathrm{t}<30)$, and the duration of drug administration, respectively.

the positive feedback loop, which perpetually maintained endogenous PKM $\zeta$ expression and enhanced EPSC amplitude.

\section{Protein synthesis inhibition}

Transient inhibition of protein synthesis does not erode the consolidated memory of a behaving animal unless the memory is recalled simultaneously with the 
inhibition [35-37]. We simulated protein synthesis inhibition in a potentiated synapse by setting $j_{1}$ to 0 during $0 \leq \mathrm{t}<540$. The duration of inhibition was based on a report that microinfusion of anisomycin into the hippocampus inhibited protein synthesis for 9 hours [38]. The simulated time courses of [PKM $\zeta$ ] and EPSC amplitude are plotted in Figures 5E and 5F. PKM $\zeta$ was degraded so slowly that only a small portion was lost while $j_{1}=0$ for 540 minutes, and the level returned to that of the UP state value when $j_{1}$ was recovered. This result is consistent with the fact that transient protein synthesis inhibition does not usually affect consolidated memory [35-37].

\section{Actin assembly inhibition}

Actin assembly inhibitors such as cytochalasins and latrunculins inhibit LTP induction [39]. We simulated the temporal application of an actin assembly inhibitor by setting $j_{2}$ and $j_{3}$ to 0 for 60 minutes. The simulated time courses are plotted in Figures $5 \mathrm{G}$ and $5 \mathrm{H}$. In agreement with experimental results, a stimulus that would have activated the PKM $\zeta$ positive feedback loop in the control condition failed to do so when actin assembly was inhibited temporarily.

\section{Reconsolidation}

Upon retrieval, well-consolidated memories become labile and vulnerable to protein synthesis inhibitors (reactivation) before they are reconsolidated [35-37]. Reactivation is thought to trigger a consolidation-like process because reactivated memory and newly acquired memory have similar time courses of susceptibility to protein synthesis inhibition: they are intact in the short term but impaired in the long term when a protein synthesis inhibitor is administered either upon retrieval or upon de novo learning [40]. A reconsolidation-like process is also observable in slice electrophysiology [41]; synapses that are potentiated by tetanus stimulation are depotentiated when stimulated again in the presence of a protein synthesis inhibitor.

These findings indicate that carrier proteins of memory traces are depleted on retrieval and replaced by newly synthesized proteins to restore memory, as suggested previously [42]. Because PKM $\zeta$ is a carrier of long-term memory, we, as well as other researchers, assumed an active mechanism that destroys PKM $\zeta$ and induces its synthesis upon retrieval $[1,13,37]$. To examine whether this assumption is consistent with previous experimental results, we simulated the time courses of [PKM $\zeta]$ and EPSC amplitude after reactivation (Figures 5I and 5J). Reactivation, which we supposed would destroy PKM $\zeta$ protein, was mimicked by clamping $[\mathrm{PKM} \zeta]$ at zero during $0 \leq \mathrm{t} \leq 10 . j_{1}$ was set at 0 when $0 \leq \mathrm{t}<540$ and at the default value otherwise to imitate transient inhibition of protein synthesis. When the synapse was reactivated by a stimulus in the presence of a protein synthesis inhibitor, EPSC amplitude approached the DOWN state, and [PKM $\zeta$ ] did not recover after treatment (solid lines). By contrast, [PKM $\zeta$ ] and EPSC amplitude recovered and ended up in the UP state, when the synapse was treated with either a reactivating stimulus (dashed lines) or a protein synthesis inhibitor alone (dotted lines). These simulated results are in line with the process of reconsolidation seen in behaving animals and brain slices [35-37,41]. However, the consistency between the simulation results and experimental data does not necessarily prove our hypothesis that newly synthesized PKM $\zeta$ replaces old PKM $\zeta$ upon reactivation. Reconsolidation might also be explained by other plausible mechanisms.

\section{Discussion}

Our model was extremely simple and lacked many of known pathways. Nevertheless, the model reproduced a variety of previous experimental results, suggesting that it captures the key characteristics of the PKM $\zeta$ network. In this section, we go a step further and propose yet to be done experiments to examine the validity of the model.

\section{Reconsolidation}

We assume that in the neuron, multiple nonlinear dynamics with various time constants are connected in tandem to store information stably and flexibly $[13,18]$. According to this model, memory reactivation switches off the slowest dynamic, the PKM $\zeta$ network, and switches on the upstream dynamics (i.e., supralinear calcium increase and calcium-activated protein kinases) on the other hand. In Figures 5I and 5J, we demonstrated the consistency between the simulation results and previous experiments to underpin our hypothesis that upon memory reactivation, newly synthesized PKM $\zeta$ replaces preexisting $\mathrm{PKM} \zeta$. It is possible to take advantage of LTP reconsolidation in vitro (see Results section) [41] and verify this hypothesis. To examine whether PKM $\zeta$ is degraded upon reactivation, hippocampal neurons are first treated with labeled amino acids, and then LTP is induced. Several hours later when LTP is consolidated, the neurons are either reactivated by another tetanus or left unstimulated (control) in the absence of labeled amino acids. According to our assumption of reactivation-triggered degradation, the amount of labeled PKM $\zeta$ will rapidly decrease in reactivated neurons whereas it will remain constant in control neurons. To prove synthesis of $\mathrm{PKM} \zeta$ upon reactivation, LTP is first induced in hippocampal neurons in the absence of labeled amino acids. Several hours later, the neurons are either reactivated or left unstimulated (control) in the presence of labeled amino acids. Our hypothesis predicts that reactivated neurons will synthesize a greater 
amount of labeled PKM $\zeta$ than control neurons, in which $\mathrm{PKM} \zeta$ is produced only to meet its turnover.

It might also be possible to examine our hypothesis in vivo; in inhibitory avoidance learning, animals are trained to associate the dark side of an experimental chamber with foot shocks, and this type of learning is known to induce LTP in the hippocampus [43]. First, the mouse PKM $\zeta$ gene is replaced with a PKM $\zeta-G F P$ chimeric gene. Then, the engineered mice are trained for an inhibitory avoidance task. Several days later, the preexisting $\mathrm{PKM} \zeta$-GFP in the hippocampus is photobleached, and the mice are divided into three groups: the reactivation group, the reactivation-protein synthesis inhibition group, and the control group. The reactivation group mice are exposed to the experimental chamber to reactivate the fear memory. Those in the reactivation-protein synthesis inhibition group are first administered a protein synthesis inhibitor and then exposed to the experimental chamber. Control mice are exposed to another chamber distinct from the one used in the training sessions. It will be possible to quantify the newly synthesized PKM $\zeta_{-G F P}$ by using fluorescence microscopy and the total PKM $\zeta$-GFP (synthesized either before or after photobleaching) by an immunological method.

Based on our hypothesis, a series of predictions can be made. In the reactivation group, PKM $\zeta$-GFP fluorescence will increase, whereas the total amount of PKM $\zeta$ GFP will remain constant. In the reactivation-protein synthesis inhibition group, both the fluorescence and total amount of the chimeric protein will decrease. In the control group, the fluorescence will stay at a low level, and the total amount of $\mathrm{PKM} \zeta-\mathrm{GFP}$ will remain constant.

\section{F-actin stabilizer}

An F-actin stabilizer such as phalloidin [44] increases the actin polymerization rate relatively to the actin depolymerization rate. To predict the effect of a F-actin stabilizer on LTP, we omitted the decay term temporarily $(0 \leq t \leq 60)$ from the ODE for $\mathrm{F}$-actin (Equation 2 ) and simulated the time courses of $[\mathrm{PKM} \zeta]$ (Figure 6A) and EPSC amplitude (Figure 6B). In the presence of the F-actin stabilizer, the system resulted in the UP state when treated with a weak stimulus that would be insufficient to turn on the network in the control condition.

Next, we investigated how the F-actin stabilizer changes the dynamics of the model. A bifurcation diagram with respect to actin stability (Figure 6C) was obtained by slicing the two-parameter $\left(j_{2}\right.$ and $\left.j_{3}\right)$ bifurcation plot (Figure 4D) with a perpendicular plane $j_{3}=\mathrm{a} j_{2}$, where " $\mathrm{a}$ " is a positive constant ( $\mathrm{a}=10$ in Figure $6 \mathrm{C}$ ). The horizontal and vertical axes of the slice show $j_{2}$ and the steady state $[\mathrm{PKM} \zeta]$, respectively. Solid circles
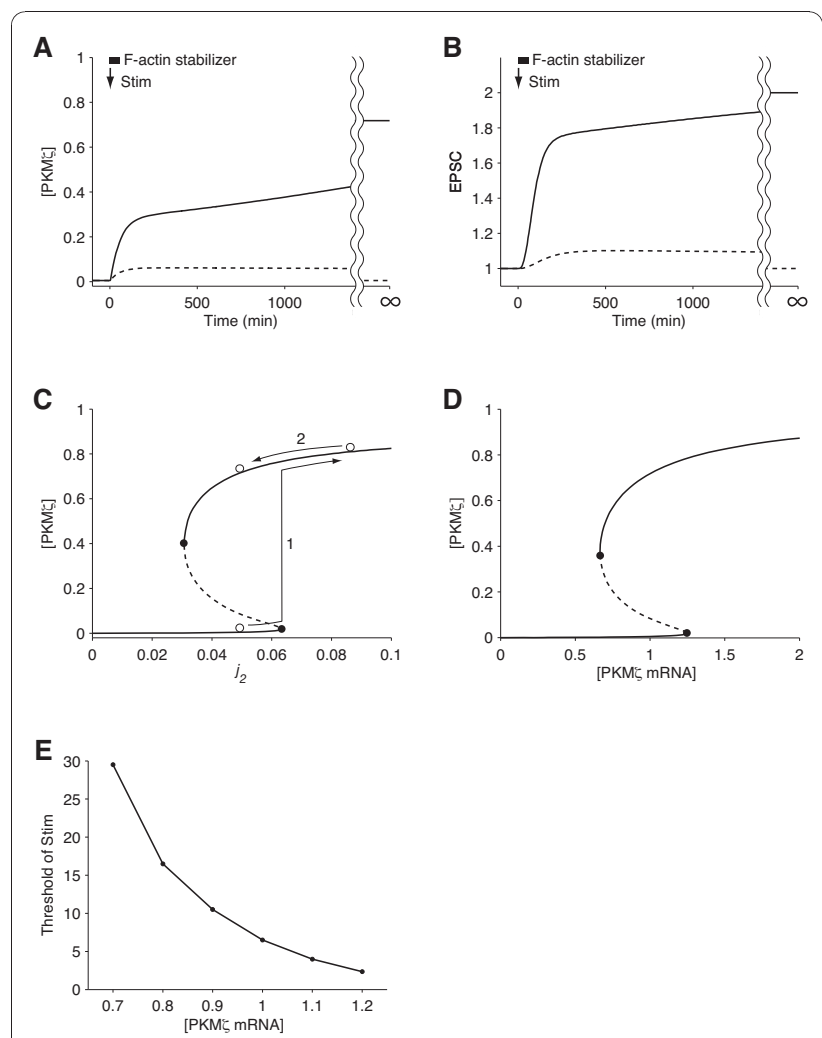

Figure 6 Simulations predicting experimental results. Time courses of A) [PKM $\zeta$ ] and B) EPSC amplitude after a weak stimulus, $\operatorname{Stim}(\mathrm{t})=5(0 \leq \mathrm{t}<30)$, in the presence (solid line) or absence (dashed line) of a F-actin stabilizer. C) Steady-state [PKM $]$ ] versus an actin polymerization rate, $j_{2}$. The other actin polymerization rate, $j_{3}$, was treated as a dependent parameter $\left(j_{3}=10 j_{2}\right)$. D, E) $[\mathrm{PKM} \zeta$ mRNA] and bistability. D) Steady-state [PKM $]$ ] versus the bifurcation

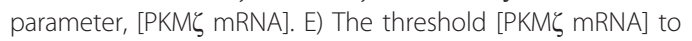
perpetually activate the system.

indicate saddle-node bifurcations. $j_{2}$ divided the dynamics of the model into three phases. The system was bistable when $j_{2}$ was between 0.031 and 0.063 and monostable when $j_{2}$ was outside of this range. A small rightward shift of $j_{2}$ from the default value did not change $[\mathrm{PKM} \zeta]$ significantly, but a large shift thrust the system beyond the right bifurcation point and brought it to the UP state (arrow 1). Subsequent withdrawal of the F-actin stabilizer did not restore the DOWN state (arrow 2) and showed hysteresis, a characteristic feature of bistable systems. These simulations predict that an F-actin stabilizer lowers the threshold of stimulation for LTP induction at low doses and induces LTP without stimuli at higher doses.

\section{Variation of mRNA concentration}

In recent years, remarkable in vivo techniques for gene transfer and local gene knockdown in the brain have been developed $[45,46]$. In our model, we assumed a 
constant level of PKM $\zeta$ mRNA, but such methods will enable variation of $[\mathrm{PKM} \zeta \mathrm{mRNA}]$. We predicted its outcome by extending the model and performing a bifurcation analysis with respect to [PKM $\zeta$ mRNA] (default value of 1) as a bifurcation parameter (Figure 6D). The dynamics of the PKM $\zeta$ network was dependent on [PKM $\zeta$ mRNA] and had three distinct phases. The system was monostable at the DOWN state when $[\mathrm{PKM} \zeta \mathrm{mRNA}]<0.67$ and at the UP state when $[\mathrm{PKM} \zeta$ mRNA] $>1.2$. The system was bistable when $0.67 \leq$ $[\mathrm{PKM} \zeta \mathrm{mRNA}] \leq 1.2$.

As [PKM $\zeta$ mRNA] increased, the saddle point approached the DOWN state (Figure 6D). One may assume that when the saddle point is closer to the DOWN state, the Stim threshold for switching on the system will be lower. Unfortunately, however, that assumption is not obvious from a two-dimensional projection (Figure 6D) of a system with many more dimensions. To obtain a clear view, we varied [PKM $\mathrm{mRNA}$ ] and found the threshold of Stim (a square wave lasting for 30 minutes) necessary for turning the system on. Figure 6E plots the threshold value of Stim against [PKM $\zeta$ mRNA]. As predicted, the concentration and input threshold were negatively correlated. It would be possible to verify this prediction in vitro and in vivo by introducing a $\mathrm{PKM} \zeta$ gene construct into the hippocampus. Moderate PKM $\zeta$ overexpression will lower the threshold for LTP induction and alter learning efficacy by increasing the sensitivity of the PKM $\zeta$ network to input, whereas an overdose of the gene will induce LTP without stimuli and hinder learning ability by destroying the bistability of the system. Silencing PKM $\zeta$ expression by RNA interference will also destroy the bistability of the system and prevent LTP and learning.

\section{Bistable positive feedback loop models}

Bistable networks are ubiquitous in biology. In particular, combination of positive feedback and nonlinearity is a very common mechanism for creating bistability. For instance, the MAPK positive feedback loop makes a bistable switch and plays crucial roles in development and memory $[14,47,48]$. Theoretical studies have demonstrated that nonlinearity of the pathway arises from dual phophorylations of the MAPK cascade; MAPK kinase kinase dually phosphorylates and activates MAPK kinase, and dually-phosphorylated MAPK kinase then dually phosphorylates MAPK $[14,49]$. CaMKII affords another example. According to a simulation study, the activity of CaMKII is bistable because its autophosphorylation provides positive feedback and the rate of autophosphorylation is nonlinearly dependent on the number of phosphorylated subunits [50]. In contrast to the MAPK and CaMKII models, our PKM $\zeta$ model is unique since bistability arises from combination of positive feedback and pathway converge (Figure 4C). Aslam et al. modeled a bistable positive feedback loop consisting of CaMKII and a translational regulator, where CaMKII autophosphorylation activates translation of CaMKII [51]. Their model is similar to ours in that translation plays a crucial role in bistability.

\section{Cerebellar long-term depression}

Long-term depression of the parallel fiber-Purkinje cell synapse is thought to be the cellular substrate of cerebellar learning [52]. Cerebellar LTD shows remarkable similarity to hippocampal LTP, although they have different directions of plasticity and involve different receptor subunits; both require large calcium transients and subsequent activation of CaMKII and PKC, and both follow AMPAR phosphorylation [52-56]. In the cerebellar Purkinje cell, stimuli induce a supralinear calcium influx, which activates MAPK and PKC in an all-ornone manner [48,57-60]. MAPK and PKC are engaged in cerebellar LTD only in the early phase (approximately 30 minutes) $[48,60]$, and what maintains LTD in the later phase is not yet known. PKM $\zeta$, the long-term memory trace in a variety of brain regions $[1,61]$, is also found in the cerebellar cortex [61], suggesting its potential involvement in cerebellar LTD $[13,18,62]$. This study mainly focuses on hippocampal L-LTP, but considering the similarity, it might also explain the mechanism for cerebellar memory.

\section{Conclusions}

We have shown here that the PKM $\zeta$ network is robustly bistable, supporting its pivotal role in long-term memory. Obviously, PKM $\zeta$ is not the sole mechanism for long-term memory; expression of various proteins, morphological changes, and synaptogenesis are also very important [63-69]. Interaction of molecular pathways that have different time scales is also important for memory stability [70]. Further experimental and computational studies will be necessary to address how these processes interact and cooperate and which process is the most crucial in retaining memory.

\section{Methods}

\section{Simulation of the biochemical reactions}

Figure 1 illustrates the pathways of the PKM $\zeta$ network model. Because qualitative data were not available for any of the pathways, we presumed the simplest case where each reaction was a first-order reaction. The following set of reactions describes the molecular interactions of the PKM $\zeta$ network. PKM $\zeta$ protein stimulates translation of its own mRNA (Figure 1 arrow 2) [25] and promotes actin polymerization (Figure 1 arrow 3 ) [26-29]. F-actin facilitates PKM $\zeta$-induced PKM $\zeta$ synthesis (Figure 1 arrow 4) [31]. Stim(t) represents the 
collective activity of protein kinases, including PKC, MAPK, and CaMKII, that induce PKM $\zeta$ expression (Figure 1 arrow 1) [2,7,12]; its basal value was 0.003 , representing the background activity of the protein kinases.

The three ODEs that describe the reactions are as follows:

$$
\begin{aligned}
& \tau_{1} \frac{d[P K M \zeta]}{d t}=j_{1}\left[R N A_{\text {active }}\right](1-[P K M \zeta])-[P K M \zeta] \\
& \tau_{2} \frac{d[\text { FActin }]}{d t}=\left(j_{2}+j_{3}[P K M \zeta]\right)(1-[\text { FActin }])-[\text { FActin }] \\
& \tau_{3} \frac{d\left[R N A_{\text {active }}\right]}{d t}=j_{4}[\text { FActin }]([P K M \zeta]+\operatorname{Stim}(t))\left(1-\left[R N A_{\text {active }}\right]\right)-\left[R N A_{\text {active }}\right]
\end{aligned}
$$

where [PKM $\zeta],[$ FActin], and [RNA active $]$ denote the concentrations of $\mathrm{PKM} \zeta$ protein, actin protein molecules assembled into F-actin, and PKM $\zeta$ mRNA recruited into the local translational machinery ('active'), respectively.

In the model, concentrations are unitless quantities. In the future, when quantitative data are available, it would be simple to convert them into quantities with units (such as micromolar). Concentrations of total actin, including F-actin and G-actin (actin monomer), and total PKM $\zeta$ mRNA (mRNA in and out of the translational machinery) are both assumed to be constant and designated values of one since neither actin or PKM $\zeta$ mRNA has been shown to increase or decrease upon LTP induction. Assuming biological regulation and resource limitation, the upper limit of [PKM $\zeta]$ was set to one. The system was still bistable without this constraint (data not shown). Time has a unit of minutes. The time constants $\tau_{1}, \tau_{2}$, and $\tau_{3}$ were determined so that PKM $\zeta$ turnover, actin polymerization, and protein synthesis would take place in realistic time scales. The parameters $j_{1}, j_{2}, j_{3}$, and $j_{4}$ denote reaction rates relative to the exponential decay of each variable: $j_{1}$ designates the PKM $\zeta$ synthesis rate, $j_{2}$ and $j_{3}$ denote the PKM $\zeta$-independent and PKM $\zeta$-dependent actin polymerization rates, respectively, and $j_{4}$ is the rate at which $\mathrm{PKM} \zeta \mathrm{mRNA}$ is incorporated into the translational machinery.

Equation 1 describes the processes in which $\mathrm{PKM} \zeta$ is translated from its active mRNA and degraded (Figure 1 arrow 1$)$. The production rate has a time scale of 10 minutes (depending on [RNA active]), which is comparable to experimental results [2]. Protein degradation was assumed to have a time scale of one day because the catalytic domain of $\mathrm{PKC} \zeta$, whose amino acid sequence is identical to that of full-length $\mathrm{PKM} \zeta$, has a half-life of at least one day [71]. Equation 2 refers to the reactions in which $\mathrm{G}$-actin is transformed to F-actin and vice versa. The forward step is at least partly dependent on $\mathrm{PKC} \zeta$ activity (Figure 1 arrow 3) [26-29]. Actin turnover in the dendritic spine was assumed to have a time scale of tens of seconds, based on previous experiments [72,73]. Equation 3 describes the process in which $\mathrm{PKM} \zeta \mathrm{mRNA}$ is recruited into translation machinery in a [PKM $]$ ]- and [FActin]dependent manner (Figure 1 arrows 2, 3) [25].

PKM $\zeta$ enhances EPSC by stabilizing AMPA receptors in postsynaptic sites through an NSF/GluR2-dependent pathway [3-5]. AMPA receptors are composed of four subunits, including two GluR2 s and two others [74,75], and NSF is thought to interact with each GluR2 subunit [76]. Therefore, we presumed that $\mathrm{PKM} \zeta$-dependent EPSC changes were a second-order reaction. EPSC was estimated by solving the following ODE:

$$
\tau_{4} \frac{d \mathrm{EPSC}}{d t}=j_{5}\left(\mathrm{EPSC}_{\mathrm{UP}}-\mathrm{EPSC}\right) \frac{[\mathrm{PKM} \zeta]^{2}}{[\mathrm{PKM} \zeta]_{\mathrm{UP}}^{2}}-\mathrm{EPSC}+j_{6}
$$

EPSC has an amplitude of 1 (arbitrary unit) in the DOWN state and an amplitude of 2 in the UP state $\left(\right.$ EPSC $\left._{\mathrm{UP}}\right)$. The decay term is based on the findings that without PKM $\zeta$ activity, EPSC amplitude in potentiated neurons approaches its baseline level $[9,25]$. The time constant $\tau_{4}$ was derived from experiments $[9,25] . j_{5}$ was set to meet the initial rate of EPSC increase after postsynaptic introduction of exogenous PKM $\zeta[9,25]$. j6 determines the basal level of EPSC.

Default parameters were represented by the following values: $\tau_{1}=1500, \tau_{2}=0.5, \tau_{3}=60, \tau_{4}=100, j_{1}=80, j_{2}=$ $0.05, j_{3}=0.5, j_{4}=0.16, j_{5}=14$, and $j_{6}=0.89$. We implemented the model equations into the software package XPPAUT [32] and performed numerical integrations and bifurcation analyses.

\section{Additional material}

Additional file 1: Time constants do not affect model equilibria. This text explains that the dynamics of the model is independent of its time constants.

\section{Acknowledgements}

We would like to thank Professor Nicolas Schweighofer of University of Southern California for helpful comments. HO was supported by a Grant-inAid for Scientific Research (KAKENHI 21700426). MK was supported by "Brain Machine Interface Development", SRBPS, MEXT.

\section{Author details}

${ }^{1}$ National Institute of Information and Communications Technology, 2-2-2, Hikaridai, Seika, Kyoto 619-0288, Japan. ${ }^{2}$ ATR Brain Information

Communication Research Laboratory Group, 2-2-2, Hikaridai, Seika, Kyoto 619-0288, Japan. ${ }^{3}$ Current Address: Pharmacovigilance Department, Astellas Pharma Inc., 3-17-1, Hasune, Itabashi, Tokyo 174-8612, Japan. 


\section{Authors' contributions}

$\mathrm{HO}$ designed and performed the study and drafted the manuscript. MK participated in the design the study and helped to draft the manuscript. Both authors read and approved the final manuscript.

Received: 9 May 2010 Accepted: 31 December 2010

Published: 31 December 2010

\section{References}

1. Sacktor TC: PKMZ, LTP maintenance, and the dynamic molecular biology of memory storage. Prog Brain Res 2008, 169:27-40.

2. Sacktor TC, Osten P, Valsamis H, Jiang X, Naik MU, Sublette E: Persistent activation of the $\zeta$ isoform of protein kinase $\mathrm{C}$ in the maintenance of long-term potentiation. Proc Natl Acad Sci USA 1993, 90:8342-8346.

3. Ling DS, Benardo LS, Sacktor TC: Protein kinase $M \zeta$ enhances excitatory synaptic transmission by increasing the number of active postsynaptic AMPA receptors. Hippocampus 2006, 16:443-452.

4. Yao Y, Kelly MT, Sajikumar S, Serrano P, Tian D, Bergold PJ, Frey JU, Sacktor TC: PKM maintains late long-term potentiation by $\mathrm{N}$ ethylmaleimide-sensitive factor/GluR2-dependent trafficking of postsynaptic AMPA receptors. J Neurosci 2008, 28:7820-7827.

5. Migues PV, Hardt O, Wu DC, Gamache K, Sacktor TC, Wang YT, Nader K: PKM maintains memories by regulating GluR2-dependent AMPA receptor trafficking. Nat Neurosci 2010, 13:630-634.

6. Muslimov IA, Nimmrich V, Hernandez Al, Tcherepanov A, Sacktor TC, Tiedge H: Dendritic transport and localization of protein kinase $M \zeta$ mRNA: implications for molecular memory consolidation. J Biol Chem 2004, 279:52613-52622.

7. Osten P, Valsamis L, Harris A, Sacktor TC: Protein synthesis-dependent formation of protein kinase $M \zeta$ in long-term potentiation. J Neurosci $1996,16: 2444-2451$.

8. Puls $A$, Schmidt $S$, Grawe $F$, Stabel S: Interaction of protein kinase $C \zeta$ with ZIP, a novel protein kinase C-binding protein. Proc Natl Acad Sci USA 1997, 94:6191-6196.

9. Serrano P, Yao Y, Sacktor TC: Persistent phosphorylation by protein kinase M maintains late-phase long-term potentiation. J Neurosci 2005, 25:1979-1984.

10. Serrano P, Friedman EL, Kenney J, Taubenfeld SM, Zimmerman JM, Hanna J, Alberini C, Kelley AE, Maren S, Rudy JW, Yin JCP, Sacktor TC, Fenton AA: PKM maintains spatial, instrumental, and classically conditioned longterm memories. PLOS Biol 2008, 6:e318.

11. Shema R, Sacktor TC, Dudai Y: Rapid Erasure of Long-Term Memory Associations in the Cortex by an Inhibitor of PKMC. Science 2007, 317:951-953.

12. Kelly MT, Crary JF, Sacktor TC: Regulation of protein kinase $M \zeta$ synthesis by multiple kinases in long-term potentiation. J Neurosci 2007. 27:3439-3444.

13. Ogasawara H, Doi T, Kawato M: Systems biology perspectives on cerebellar long-term depression. NeuroSignals 2008, 16:300-317.

14. Bhalla US, lyengar R: Emergent properties of networks of biological signaling pathways. Science 1999, 283:381-387.

15. Ferrell JE Jr: Building a cellular switch: more lessons from a good egg. Bioessays 1999, 21:866-870

16. Crick F: Memory and molecular turnover. Nature 1984, 312:101.

17. Lisman JE: A mechanism for memory storage insensitive to molecular turnover: a bistable autophosphorylating kinase. Proc Natl Acad Sci USA 1985, 82:3055-3057.

18. Ogasawara H, Kawato M: Computational models of cerebellar long-term memory. In Systems Biology: The Challenge of Complexity. Edited by: Nakanishi S, Kageyama R, Watanabe D. New York: Springer; 2009:169-182.

19. Gamble $E$, Koch C: The dynamics of free calcium in dendritic spines in response to repetitive synaptic input. Science 1987, 236:1311-1315.

20. Chetkovich DM, Gray R, Johnston D, Sweatt JD: N-methyl-D-aspartate receptor activation increases CAMP levels and voltage-gated $\mathrm{Ca}^{2+}$ channel activity in area CA1 of hippocampus. Proc Natl Acad Sci USA 1991, 88:6467-6471.

21. Yuste R, Majewska A, Cash SS, Denk W: Mechanisms of calcium influx into hippocampal spines: heterogeneity among spines, coincidence detection by NMDA receptors, and optical quantal analysis. $J$ Neurosci 1999, 19:1976-1987.
22. Rae MG, Martin DJ, Collingridge GL, Irving AJ: Role of $\mathrm{Ca}^{2+}$ stores in metabotropic L-glutamate receptor-mediated supralinear $\mathrm{Ca}^{2+}$ signaling in rat hippocampal neurons. J Neurosci 2000, 20:8628-8636.

23. Xia Z, Storm DR: The role of calmodulin as a signal integrator for synaptic plasticity. Nat Rev Neurosci 2005, 6:267-276.

24. Lisman J, Spruston N: Postsynaptic depolarization requirements for LTP and LTD: a critique of spike timing-dependent plasticity. Nat Neurosci 2005, 8:839-841.

25. Ling DS, Benardo LS, Serrano PA, Blace N, Kelly MT, Crary JF, Sacktor TC: Protein kinase $M \zeta$ is necessary and sufficient for LTP maintenance. Nat Neurosci 2002, 5:295-296.

26. Gómez J, Martínez de Aragón A, Bonay P, Pitton C, García A, Silva A Fresno M, Alvarez F, Rebollo A: Physical association and functional relationship between protein kinase $\mathrm{C} \zeta$ and the actin cytoskeleton. Eur J Immunol 1995, 25:2673-2678.

27. Wang HR, Zhang Y, Ozdamar B, Ogunjimi AA, Alexandrova E, Thomsen GH, Wrana JL: Regulation of cell polarity and protrusion formation by targeting RhoA for degradation. Science 2003, 302:1775-1779.

28. Chodniewicz D, Zhelev DV: Chemoattractant receptor-stimulated F-actin polymerization in the human neutrophil is signaled by 2 distinct pathways. Blood 2003, 101:1181-1184.

29. Sun R, Gao P, Chen L, Ma D, Wang J, Oppenheim JJ, Zhang N: Protein kinase $C \zeta$ is required for epidermal growth factor-induced chemotaxis of human breast cancer cells. Cancer Res 2005, 65:1433-1441.

30. Stapulionis R, Kolli S, Deutscher MP: Efficient mammalian protein synthesis requires an intact F-actin system. J Biol Chem 1997, 272:24980-24986.

31. Kelly MT, Yao Y, Sondhi R, Sacktor TC: Actin polymerization regulates the synthesis of PKM in LTP. Neuropharmacology 2007, 52:41-45.

32. Ermentrout B: Simulating, Analyzing, and Animating Dynamical Systems: A Guide to XPPAUT for Researchers and Students. 1 edition. Society for Industrial Mathematics; 2002.

33. Fall CP, Marland ES, Wagner JM, Tyson JJ: Computational Cell Biology New York: Springer-Verlag; 2002

34. Kuznetsov YA: Elements of applied bifurcation theory. 3 edition. New York: Springer; 2004

35. Sara SJ: Retrieval and reconsolidation: toward a neurobiology of remembering. Learn Mem 2000, 7:73-84.

36. Tronson NC, Taylor JR: Molecular mechanisms of memory reconsolidation. Nat Rev Neurosci 2007, 8:262-275.

37. Nader $\mathrm{K}$, Hardt O: A single standard for memory: the case for reconsolidation. Nat Rev Neurosci 2009, 10:224-234.

38. Wanisch K, Wotjak CT: Time course and efficiency of protein synthesis inhibition following intracerebral and systemic anisomycin treatment. Neurobiol Learn Mem 2008, 90:485-494.

39. Krucker T, Siggins GR, Halpain S: Dynamic actin filaments are required for stable long-term potentiation (LTP) in area CA1 of the hippocampus. Proc Natl Acad Sci USA 2000, 97:6856-6861.

40. Debiec J, LeDoux JE, Nader K: Cellular and systems reconsolidation in the hippocampus. Neuron 2002, 36:527-538.

41. Fonseca R, Nagerl UV, Bonhoeffer T: Neuronal activity determines the protein synthesis dependence of long-term potentiation. Nat Neurosci 2006, 9:478-480.

42. Arshavsky Yl: Long-term memory: does it have a structural or chemical basis? Trends Neurosci 2003, 26:465-466, author reply 466-468.

43. Whitlock JR, Heynen AJ, Shuler MG, Bear MF: Learning induces long-term potentiation in the hippocampus. Science 2006, 313:1093-1097.

44. Wehland J, Osborn M, Weber K: Phalloidin-induced actin polymerization in the cytoplasm of cultured cells interferes with cell locomotion and growth. Proc Natl Acad Sci USA 1977, 74:5613-5617.

45. Hommel JD, Sears RM, Georgescu D, Simmons DL, DiLeone RJ: Local gene knockdown in the brain using viral-mediated RNA interference. Nat Med 2003, 9:1539-1544.

46. Le Gal La Salle G, Robert JJ, Berrard S, Ridoux V, Stratford-Perricaudet LD, Perricaudet $\mathrm{M}$, Mallet J: An adenovirus vector for gene transfer into neurons and glia in the brain. Science 1993, 259:988-990.

47. Ferrell JE Jr, Machleder EM: The biochemical basis of an all-or-none cell fate switch in Xenopus oocytes. Science 1998, 280:895-898.

48. Kuroda S, Schweighofer N, Kawato M: Exploration of signal transduction pathways in cerebellar long-term depression by kinetic simulation. $J$ Neurosci 2001, 21:5693-5702. 
49. Huang $C Y$, Ferrell JE Jr: Ultrasensitivity in the mitogen-activated protein kinase cascade. Proc Natl Acad Sci USA 1996, 93:10078-10083.

50. Miller P, Zhabotinsky AM, Lisman JE, Wang XJ: The stability of a stochastic CaMKII switch: dependence on the number of enzyme molecules and protein turnover. PLoS Biol 2005, 3:e107.

51. Aslam N, Kubota Y, Wells D, Shouval HZ: Translational switch for longterm maintenance of synaptic plasticity. Mol Syst Biol 2009, 5:284

52. Ito M: Cerebellar long-term depression: characterization, signal transduction, and functional roles. Physiol Rev 2001, 81:1143-1195.

53. Malenka RC, Bear MF: LTP and LTD: an embarrassment of riches. Neuron 2004, 44:5-21.

54. Lynch MA: Long-term potentiation and memory. Physiol Rev 2004, 84:87-136.

55. Hansel C: When the B-team runs plasticity: GluR2 receptor trafficking in cerebellar long-term potentiation. Proc Natl Acad Sci USA 2005, 102:18245-18246.

56. Hansel C, de Jeu M, Belmeguenai A, Houtman SH, Buitendijk GH, Andreev D, De Zeeuw Cl, Elgersma Y: aCaMKII is essential for cerebellar LTD and motor learning. Neuron 2006, 51:835-843.

57. Kotaleski JH, Lester D, Blackwell KT: Subcellular interactions between parallel fibre and climbing fibre signals in Purkinje cells predict sensitivity of classical conditioning to interstimulus interval. Integr Physiol Behav Sci 2002, 37:265-292.

58. Doi T, Kuroda S, Michikawa T, Kawato M: Inositol 1,4,5-trisphosphatedependent $\mathrm{Ca}^{2+}$ threshold dynamics detect spike timing in cerebellar Purkinje cells. J Neurosci 2005, 25:950-961.

59. Tanaka K, Khiroug L, Santamaria F, Doi T, Ogasawara H, Ellis-Davies GC, Kawato $\mathrm{M}$, Augustine $\mathrm{GJ}: \mathrm{Ca}^{2+}$ requirements for cerebellar long-term synaptic depression: role for a postsynaptic leaky integrator. Neuron 2007, 54:787-800.

60. Tanaka K, Augustine GJ: A positive feedback signal transduction loop determines timing of cerebellar long-term depression. Neuron 2008, 59:608-620.

61. Oster H, Eichele G, Leitges M: Differential expression of atypical PKCs in the adult mouse brain. Brain Res Mol Brain Res 2004, 127:79-88.

62. Ogasawara H, Kawato M: Bistable Switches for Synaptic Plasticity. Sc Signal 2009, 2:pe7-

63. Kasai H, Matsuzaki M, Noguchi J, Yasumatsu N, Nakahara H: Structurestability-function relationships of dendritic spines. Trends Neurosci 2003, 26:360-368.

64. Segal M: Dendritic spines and long-term plasticity. Nat Rev Neurosci 2005, 6:277-284.

65. Hernandez PJ, Abel T: The role of protein synthesis in memory consolidation: progress amid decades of debate. Neurobiol Learn Mem 2008, 89:293-311.

66. Saneyoshi T, Fortin DA, Soderling TR: Regulation of spine and synapse formation by activity-dependent intracellular signaling pathways. Cur Opin Neurobiol 2009, 20:1-8.

67. Xu T, Yu X, Perlik AJ, Tobin WF, Zweig JA, Tennant K, Jones T, Zuo Y: Rapid formation and selective stabilization of synapses for enduring motor memories. Nature 2009, 462:915-919.

68. Yang G, Pan F, Gan WB: Stably maintained dendritic spines are associated with lifelong memories. Nature 2009, 462:920-924

69. Jaworski J, Kapitein LC, Gouveia SM, Dortland BR, Wulf PS, Grigoriev I, Camera P, Spangler SA, Di Stefano P, Demmers J, Krugers H, Defilippi P, Akhmanova A, Hoogenraad CC: Dynamic Microtubules Regulate Dendritic Spine Morphology and Synaptic Plasticity. Neuron 2009, 61:85-100.

70. Jain P, Bhalla US: Signaling logic of activity-triggered dendritic protein synthesis: an mTOR gate but not a feedback switch. PLoS Comput Biol 2009, 5:e1000287.

71. Le Good JA, Brindley DN: Molecular mechanisms regulating protein kinase Czeta turnover and cellular transformation. Biochem J 2004, 378:83-92.

72. Star EN, Kwiatkowski DJ, Murthy VN: Rapid turnover of actin in dendritic spines and its regulation by activity. Nat Neurosci 2002, 5:239-246.

73. Tatavarty V, Kim EJ, Rodionov V, Yu J: Investigating sub-spine actin dynamics in rat hippocampal neurons with super-resolution optical imaging. PLoS One 2009, 4:e7724

74. Mayer ML: Glutamate receptor ion channels. Curr Opin Neurobiol 2005, 15:282-288.
75. Greger IH, Ziff EB, Penn AC: Molecular determinants of AMPA receptor subunit assembly. Trends Neurosci 2007, 30:407-416.

76. Zhao C, Slevin JT, Whiteheart SW: Cellular functions of NSF: not just SNAPs and SNAREs. FEBS Lett 2007, 581:2140-2149.

doi:10.1186/1752-0509-4-181

Cite this article as: Ogasawara and Kawato: The protein kinase $M \zeta$ network as a bistable switch to store neuronal memory. BMC Systems Biology 2010 4:181.

\section{Submit your next manuscript to BioMed Central and take full advantage of:}

- Convenient online submission

- Thorough peer review

- No space constraints or color figure charges

- Immediate publication on acceptance

- Inclusion in PubMed, CAS, Scopus and Google Scholar

- Research which is freely available for redistribution

Submit your manuscript at www.biomedcentral.com/submit
Ciomed Central 